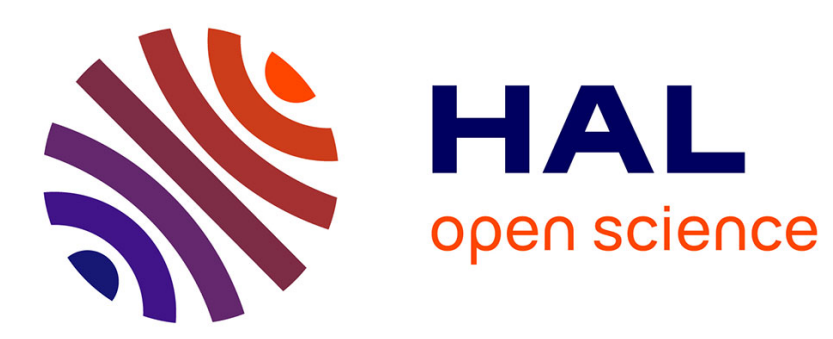

\title{
Conformational changes in ammonia-channeling glutamine amidotransferases
}

Stéphane Mouilleron, Béatrice Golinelli-Pimpaneau

\section{To cite this version:}

Stéphane Mouilleron, Béatrice Golinelli-Pimpaneau. Conformational changes in ammonia-channeling glutamine amidotransferases. Current Opinion in Structural Biology, 2007, 17 (6), pp.653 - 664. 10.1016/j.sbi.2007.09.003 . hal-03283042

\section{HAL Id: hal-03283042 \\ https://hal.science/hal-03283042}

Submitted on 9 Jul 2021

HAL is a multi-disciplinary open access archive for the deposit and dissemination of scientific research documents, whether they are published or not. The documents may come from teaching and research institutions in France or abroad, or from public or private research centers.
L'archive ouverte pluridisciplinaire HAL, est destinée au dépôt et à la diffusion de documents scientifiques de niveau recherche, publiés ou non, émanant des établissements d'enseignement et de recherche français ou étrangers, des laboratoires publics ou privés. 
Conformational changes in ammonia-channeling glutamine amidotransferases. Stéphane Mouilleron ${ }^{1,2}$, Béatrice Golinelli-Pimpaneau ${ }^{1}$

${ }^{1}$ Laboratoire d'Enzymologie et Biochimie structurales, CNRS Bâtiment 34, 1 avenue de la Terrasse, 91190 Gif-sur-Yvette, France

Corresponding author: Béatrice Golinelli-Pimpaneau, tel: 3316982 42 35, fax: 33 1698231 29, e-mail: beatrice.golinelli@lebs.cnrs-gif.fr

2 Present address: Structural Biology Laboratory, Cancer Research UK, London Research Institute, 44 Lincoln's Inn Fields, London WC2A 3PX, United Kingdom

Running title: Ammonia-channeling glutamine amidotransferases. 


\section{Abstract}

Glutamine amidotransferases, which catalyze the synthesis of different aminated products, channel ammonia over 10-40 $\AA$ from a glutamine substrate at the glutaminase site to an acceptor substrate at the synthase site. Ammonia production usually uses a cysteine-histidine-glutamate triad, or a $\mathrm{N}$-terminal cysteine residue. Crystal structures of several amidotransferase.ligand complexes, mimicking intermediates along the catalytic cycle, have now been determined. In most cases, acceptor binding triggers glutaminase activation through domain hinged-movements and other conformational changes. Structural information shows how flexible loops of the synthase and glutaminase domains move to shield the two catalytic sites and anchor the substrates, and how the ammonia channel forms, and opens or closes.

\section{Key words}

Ammonia channeling/interdomain signaling/catalytic coupling/glutamine amidotransferases/ hinge motion

\section{Abbreviations}

AS: anthranilate synthase; AsnB: asparagine synthetase B; AT: amidotransferase; CPS: carbamoyl-phosphate synthetase; CTPS: CTP synthetase; DON: 6-diazo-5oxo-L-nor-leucine; GItS: glutamate synthase; GIn: L-glutamine; GSA: glutamyl- $\gamma$ semialdehyde; Fru6P: D-fructose-6-phosphate; Fd-GltS: ferredoxin-dependent glutamate synthase; FGAM: formylglycinamidine ribonucleotide; FGAR: formylglycinamide ribonucleotide; FGAR-AT: formylglycinamidine ribonucleotide amidotransferase; GAT: glutamine amidotransferase; GatCAB: bacterial Glu-tRNA ${ }^{\text {Gln }}$ amidotransferase; GatDE: archaeal Glu-tRNA ${ }^{\text {Gln }}$ amidotransferase; G3P: glyceraldehyde-3-phosphate; GImS: glucosamine-6-phosphate synthase; GPAT: glutamine phosphoribosylpyrophosphate amidotransferase; GMPS: GMP synthetase; Ntn: amino-terminal nucleophile ; IGP: imidazole glycerol phosphate; 
IGPS: imidazole glycerol phosphate synthase ; 2-OG: 2-oxo-glutarate ; PLPS: PLP synthase ; PRA: 5-phosphoribosyl-( $\beta$ )1-amine ; PRFAR: $N^{1}-\left(5^{\prime}\right.$-phosphoribosyl)formimino-5-aminoimidazole-4-carboxamide ribonucleotide ; PRPP: 5phosphoribosyl-( $\alpha$ )1-pyrophosphate ; R5P: ribulose-5-phosphate 


\section{Introduction}

Glutamine amidotransferases (GATs) play a central role in metabolism since these enzymes are responsible for the incorporation of nitrogen into amino acids, amino sugars, purine and pyrimidine nucleotides, coenzymes and antibiotics (Table 1). The enzymes consist of at least two globular domains or subunits. Hydrolysis of glutamine in the glutaminase domain yields ammonia, which is transferred to a synthase (or ATP-dependent synthetase) domain specific for each GAT through a channel, which is usually $10-40 \AA$ long. The catalytic mechanism consists generally of the nucleophilic attack of the thiol group of a catalytic cysteine residue on the $\delta$ carbonyl group of glutamine to form ammonia, that is next transferred through the channel to act as a nucleophile on an $\mathrm{NH}_{3}$ acceptor substrate, which differs for each GAT [1]. Depending on the active sites residues, GATs are categorized into different unrelated classes (Table 1): class I or triad GATs use histidine and glutamate residues for the activation of the cysteine thiol group (Fig. 1A) whereas in class II or $\mathrm{N}$-terminal nucleophile (Ntn) GATs, the catalytic cysteine is at the N-terminus and its thiol group is activated by the $\alpha$-amino group (Fig. 1B). Other families of GATs, related to amidases [2], L-asparaginases [3], or nitrilases [4] also exist. The glutaminase domain of most triad GATs shares a common open $\alpha / \beta$ structure fold whereas that of Ntn GATs is composed mainly of antiparallel $\beta$-sheets.

Interdomain signaling mechanisms are common to all enzymes that use substrate channeling [5-8]. These ensure the efficacy of the reaction, since the substrate to be channeled is not produced until the acceptor is ready for the transfer, and it is then rapidly diffused from one active site to the other through the channel. In addition, the solvent-inaccessible ammonia channel in GATs prevents the formation of nonreactive ammonium ions. Hence the enzymes must synchronize their catalytic sites through conformational changes triggered by acceptor or glutamine binding. Recently, new structures of GATs have been reported, as well as new complexes of previously structurally characterized enzymes (Table 2). Here we provide an 
overview of the progress made in understanding the conformational changes necessary for shielding the active sites, activating the glutaminase function and forming the channel, based on the crystallographic structures.

\section{Structural changes upon acceptor binding}

\section{Closure of the synthase site by a flexible loop}

The conformational changes that occur in the synthase site upon acceptor binding can be visualized by comparing the structures of the enzyme alone and in the presence of acceptor substrate. Although there are none amidotransferases for which both structures have been reported yet (Table 2), we recently solved the structure of unliganded E. coli glucosamine-6-P synthase (GImS) (S Mouilleron et al., unpublished), in which the glutaminase domains are disordered, as well as the synthase C-terminal nonapeptide. Comparison with the acceptor-bound structure [9••] indicates that these elements become ordered upon acceptor binding and that the C-terminal loop covers the synthase site and forms also the major part of the channel (Fig. 2A).

In addition, the structure of glutamine phosphoribosylpyrophosphate amidotransferase (GPAT) in the presence of the glutamine affinity analog 6-diazo-5oxo-L-nor-leucine (DON) can be compared to that in the presence of both DON and acceptor substrate and give hints about the conformational changes occurring upon acceptor binding. The occupation of the synthase site of GPAT triggers the ordering of a 25-residues flexible loop, which closes the synthase site and forms one wall of the channel [10,11] (Fig. 2B).

Although the acceptor-bound form of yeast imidazole glycerol phosphate synthase (IGPS), which also contains a glutamine analog, represents only a precatalytic form of the enzyme, the comparison of the acceptor-bound and free forms of IGPS indicates that several loops surrounding the active site move slightly toward the acceptor substrate when it binds, the largest conformational change being a reorientation of the partially ordered synthase site loop connecting strand $\beta 1$ to helix 
$\alpha 1$ [12]. This structural change, which is also observed by comparing the synthase sites in the three molecules in the asymmetric unit of T. maritima IGPS, in which either one or two phosphate ions are bound at the synthase site [13], causes the side chain of Lys258 of the synthase loop to point into the synthase site and interact with the acceptor substrate.

Recently, several structures of Glu-tRNA ${ }^{\text {Gln }}$ GATs have been reported (Table 2). Bacterial Glu-tRNA ${ }^{\text {Gln }}$ GATs are heterotrimeric proteins composed of $A, B, C$ subunits (GatCAB) while archaeal enzymes are heterodimeric proteins composed of $D$ and $E$ subunits (GatDE). Whereas the synthetase subunits, GatB and GatE, are highly related, ammonia production is achieved by the structurally different GatA and GatD subunits. The flexible synthetase 120-residues C-terminal region is ordered in the tRNA ${ }^{\text {Gln }}$-bound GatDE structure and interacts with $\operatorname{tRNA}^{\text {Gln }}$ [14•], while it is disordered in the unliganded GatDE [15] and in the unliganded or GIn-bound GatCAB structures [16•]. Therefore, the synthetase tail domain becomes ordered upon Glu-tRNA ${ }^{\text {Gln }}$ acceptor binding.

Other examples indicating the closure of the synthase site upon acceptor binding come from the comparison of different complexed states of enzymes from different species (Fig. 2C, D and E). In addition, the existence of a flexible loop, which should close on the synthase site, is indicated by its disorder in the structure in the absence of the acceptor substrate and by the accessibility of the synthase site to solvent. For example, the 37-terminal residues of the synthetase domain of asparagine synthetase B (AsnB) in complex with glutamine and AMP [17] and a 22-residues peptide of the synthetase domain of GMP synthetase (GMPS) in the absence of acceptor and donor substrates [18] are disordered, and were suggested to be stabilized upon acceptor binding. Likewise, a large conformational change upon ATP and acceptor binding is expected in $T$. thermophilus CTP synthetase (CTPS) because no continuous channel connects the synthase and glutaminase sites, the synthetase active site is exposed to solvent and the binding pocket for the allosteric effector GTP is not properly formed [19]. 


\section{Stimulation of the glutaminase function upon acceptor binding.}

GATs employ different mechanisms to incapacitate their glutaminase function until an activation signal is received from the remote synthase site. The glutaminase activity is usually coupled with acceptor binding to the synthase site, although there are quantitative differences as to the degree of the glutaminase regulation (Supplementary Table 1, Fig. 1C). It has also been demonstrated in a few cases, that inactivation by glutamine affinity analogs is dependent upon acceptor binding or that acceptor binding is followed by glutamine binding [1]. The mechanism of activation of the glutaminase function upon acceptor binding varies among GATs and comes from an increase of $k_{c a t}$, a lowering of $K_{m}{ }^{G l n}$ or both and involves protein conformational changes upon acceptor binding at the synthase site to reorganize the glutaminase site.

\section{Catalytic coupling}

\section{Formation of the glutaminase pocket}

Glutamine binding results in the closure of the glutaminase site by a flexible loop (Qloop) in Ntn GATs (Fig. 1B). Likewise, for some triad GATs such as IGPS [12] and CTPS [19], a loop of the glutaminase domain becomes ordered or is reorganized upon glutamine or glutamine analog binding to cover the entrance of the glutaminase site and shield glutamine.

To control glutaminase activity, glutamine is bound in a non-productive orientation in the absence of the acceptor substrate, and a specificity pocket is created only at the appropriate point in the catalytic cycle. Thus, in CTPS, a tyrosine from the synthase domain becomes ordered only in the presence of glutamine and participates in the glutaminase active site formation by interacting with the glutamine amide group [19]. Moreover, it was suggested that the glutaminase site of $S$. typhimurium anthranilate synthase (AS) would be fully formed only in the presence of acceptor substrate since parts of the glutaminase site are disordered in its absence [20]. In addition, comparing the structures of DON-inactivated GPAT in the absence and in the 
presence of stable acceptor analog $[10,21]$ shows that the glutamine anchoring site is formed only when the acceptor is bound, through the positioning of several glutamine-binding residues (Fig. 1C). Finally, the presence in the structure of $S$. thyphimurium FGAR-AT of a glutamylthioester intermediate together with a water molecule positioned to hydrolyze the thioester intermediate indicates that the reaction did not take place and suggests that completion of the reaction requires a conformational change associated with acceptor binding [22].

\section{Positioning of the catalytic residues}

Another way GATs use to regulate glutamine hydrolysis is to optimally position the catalytic residues and the oxyanion hole (comprising two amide nitrogens, which stabilize the transient negative charge developing on the carbonyl oxygen during glutamine hydrolysis), only after acceptor is bound. Because acceptor binding stimulates glutamine hydrolysis, the conformational changes occurring upon glutamine binding that lead to catalysis in GATs can be visualized by comparing the structures in the presence of acceptor, and in the presence of both acceptor and glutamine analogs, which represents the active conformation of the enzyme before the ammonia transfer step. Such structures have been determined for only two Ntn ATs, GImS and ferredoxin-dependent glutamate synthase (Fd-GItS).

Glutamine binding to GImS activates the glutaminase function by positioning the oxyanion hole asparagine residue through a $100^{\circ}$ rotation of its side chain, and by enhancing the nucleophilic character of the $\alpha$-amino group of Cys 1 [9••]. Similarly, it has been suggested that upon acceptor binding to Fd-GItS, the $\alpha$-amino group of Cys 1 would be activated by a hydrogen bond with residue Glu1013 of loop 4 from the synthase domain, due to a movement of this loop [23]. Nevertheless, the oxyanion hole asparagine is in an active conformation when the glutaminase site is empty in Fd-GltS [24] and when the synthase site is empty in GPAT [21] and AsnB [17].

There are other hints indicating that conformational changes in the glutaminase site are necessary to activate the glutaminase function. Thus, in the structure of IGPS in 
complex with a glutamine analog but no acceptor substrate, the glutaminase site is not in a fully active state because the oxyanion hole is not completely formed [25]. It has been proposed that a conformational change induced by acceptor binding would reorganize the oxyanion strand and form the oxyanion hole [12]. In addition, the glutaminase site is closed in unliganded AS [26]. Therefore, conformational changes accompanying acceptor binding could force the glutaminase subunit to switch from a nonfunctional to a functional conformation, allowing glutamine to enter and be hydrolyzed.

\section{A synthase flexible loop is involved in the coupling of the two catalytic sites}

In all GATs, the communication between the two active sites is mediated by residues, which constitute the ammonia channel. For instance, in GImS, the Cterminal residues, in particular Thr606, the only residue from the synthase domain taking part to the glutaminase site (Fig. 1B), and Lys603, whose peptide bond flips

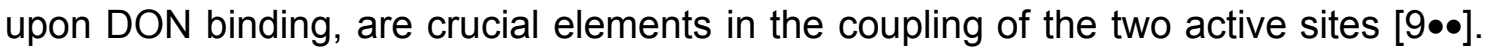
In Fd-GltS, Glu1013 (equivalent to Thr606 of GImS, Fig. 1B) at the C-terminus of loop 4 of the synthase domain, which covers the synthase site and forms part of the wall of the channel [24], has been shown to be crucial for glutaminase activation and coupling of the glutaminase and synthase sites [27]. In GPAT, Ile335 belonging to the synthase flexible loop, which covers the synthase site, is involved in the activation of the glutaminase function by contacting Tyr74 of the Q-loop (Fig. 2B), which leads to the repositioning of Arg73 to interact with the $\alpha$-carboxyl group of glutamine (Fig. 1C). Finally, in IGPS, Lys258, which belongs to a synthase loop covering the synthase site and is positioned to interact with the acceptor substrate when it binds, has been shown by mutagenesis to be implicated in signaling [28].

\section{Hinge movement}

Hinge domain motions involved in coupling catalysis in the two remote active sites have been demonstrated for GImS by comparing the structures of GImS in complex with acceptor and in complex with both acceptor and DON (Supplementary Fig. 1A) $[9 \bullet \bullet, 29 \bullet]$. This domain rotation of $23^{\circ}$ is necessary to allow the closure of the Q-loop 
over the glutaminase site without changing the dimer interface. Hinge movements of the synthase and glutaminase domains relative to each other seem to be a general property of GATs because partially closed conformations have been observed for sulfate-bound CTPS, and for IGPS in complex with acceptor substrate and glutamine analog (Supplementary Fig. 1B and 1C).

\section{Conformational changes upon complex assembly}

Several conformational changes occur also during assembly of the enzymatic complex from different subunits or during oligomerization to form an active enzyme. Thus, the recently reported structures of PLPS from B. subtilis and T. maritima $[30 \bullet \bullet, 31 \bullet \bullet]$ can be compared to the structures of the individual synthase $[30 \bullet \bullet, 32]$ and glutaminase subunits $[30 \bullet \bullet, 33,34]$ from several organisms to shade light on the conformational changes occuring upon complex assembly. Upon complexation with the glutaminase subunit, the 18-residues $\mathrm{N}$-terminus of the synthase subunit becomes ordered, as well as an extra helix $\alpha 2$ '. In fact, the N-terminal $\alpha$-helix on the synthase subunit directs the macromolecular assembly of twelve synthase and twelve glutaminase subunits in PLPS and also forms one side of the putative ammonia channel (Supplementary Fig. 2). Moreover, the formation of the oxyanion hole, which is linked to the conformational change of the $\mathrm{N}$-terminal $\alpha$-helix, occurs only upon complexation with the synthase subunit. Similarly, a reactive conformation of the oxyanion hole is observed for GImS [9••] and not for the glutaminase subunit alone [35].

Then, comparison of the structures of yeast IGPS and T. maritima glutaminase subunit alone [36], as well as mutagenesis studies [37], suggest that a lysine residue belonging to the glutaminase loop carrying the His and Glu catalytic residues may regulate the glutaminase function upon association of the glutaminase and synthase domains by altering the loop conformation [37].

Finally, in the absence of ATP and acceptor substrate, CTPS maintains an equilibrium between monomer, dimer and tetramer states in solution while in their presence or in the crystal, the enzyme folds into an active homotetramer, with the 
walls of the synthase active site contributed by three different subunits [19].

\section{Formation of the channel}

Distinct ammonia channels are used by GATs because the channels are formed primarily by the synthase domains, which are not related to each other (Fig. 3).

Significant conformational changes accompanying substrate binding are required for the formation of the channel in most GATs.

However, the channels are apparent in some structures in the absence of acceptor, like in carbamoyl-phosphate synthetase (CPS) [38] and AsnB [17]. Nevertheless, in the unliganded structures of IGPS, the channel is formed but obstructed by four charged residues forming a salt-bridge ring that serve as a gate between the two domains (Fig. 3A) [12,13,39,40]. Acceptor binding has been suggested to induce the opening of the IGPS channel. In contrast, channel formation is dependent on acceptor binding in GPAT [10] or GImS (Fig. 3B) (S Mouilleron et al., unpublished) because the flexible loop that closes the synthase site upon acceptor binding is a major component of the channel. In Fd-GItS and NADPH-GItS, the channel, which is formed by residues belonging to loop 4 also involved in acceptor binding [23], is fully formed but is unfortunately obstructed by the C-terminal residues of loop 4 in the structure in complex with DON and acceptor because of crystal packing constraints [24] (Fig. 3C). Yet, the channel is expected to open upon substrate(s) binding.

In the unliganded E. coli CTPS structure, two cavities in the glutaminase and synthase domains define an apparent ammonia diffusion path (Fig. 3D) [41] whereas in T. thermophilus CTPS, the channel is not formed. In GMPS, both active sites are exposed to solvent and the channel is not apparent [18]. Likewise, some conformational changes are needed in AS [20,26] or PLPS (Supplementary Fig. 2) $[30 \bullet \bullet, 31 \bullet \bullet]$ to create a continuous channel from the observed adjacent cavities. In FGAR-AT, two possible paths for ammonia exist through a gate formed by two phenylalanine residues [22]. 


\section{Opening of the ammonia channel}

Although the mechanism of ammonia channel opening has been unveiled only for a few GATS, a model for it has be proposed in a few other cases.

The C-terminal loop of GImS forms part of the ammonia channel, connecting the two active sites. In the presence of the acceptor alone, the channel of GImS is totally closed by the indole ring of Trp74, which explains why GImS cannot use ammonia as a nitrogen donor. DON binding induces the opening of the ammonia channel through rotation of the Trp74 indole side-chain, allowing the connection between the two active sites (Fig. 3B) [9••]. An opening mechanism of the same amplitude to that occurring in GImS has been observed for an indole-channeling enzyme, tryptophan synthase (Fig. 3E) [42].

In GPAT, the residue equivalent to Trp74 in GIms, Tyr74, lines the ammonia channel and has been shown by mutagenesis experiments to be a key residue in coupling the glutamine and acceptor sites upon acceptor binding [21]. In GPAT, Tyr74 may play a similar gate role as Trp74 in GImS.

In E. coli CTPS, His57 has been proposed to act as the gate of the channel because it can adopt two different conformations that open or close the ammonia channel (Fig. 3D)[41].

Of the four charged residues blocking the channel in IGPS (Fig. 3A), the lysine residue is the most plausible candidate for the door of the channel $[25,40]$ because it displays the largest conformational flexibility in the crystal structures of the enzyme [40], and it adopts two different conformations in the structure of the isolated synthase subunit of T. maritima IGPS. In one of them, which may represent the open conformation of the channel, it is free from the cyclic salt bridge and makes a $\mathrm{H}$-bond with a residue of the synthase domain.

\section{Other conformational changes}

In addition, other conformational changes involving other steps of the reaction, such as ATP binding to the synthetase domain, exist. For instance, a flexible loop of 
FGAR-AT partially shields ATP from solvent upon complex formation [22]. Moreover, different conformations of the B-domain of the carboxyphosphate synthetic unit in CPS are observed depending on its liganded state [38,43,44]: occupation of the phosphate-binding site by inorganic phosphate or by a non-hydrolyzable analog of ATP triggers the closure of the B-domain of both synthetic units over the active-site pocket.

\section{Conclusion}

The main functional feature of GATs is their ability to coordinate the activity of their two functional sites in order to avoid a wasteful consumption of glutamine [1]. Generally, hydrolysis of glutamine occurs significantly only when the acceptor is bound to the synthase domain, initiating an interdomain signal transduction that activates the glutaminase function. Thus, the active conformation of the glutaminase site is achieved only after acceptor binding. In GATs, flexible loops of the synthase and glutaminase domains seem to function as gates to give access to the active site only at proper time by adopting open and closed conformations. Yet, the ammonia channel is formed and open at different moments during catalysis, for each GAT. 


\section{Figure legends}

Fig. 1: Comparison of the glutaminase active sites in triad GATs and Ntn GATs.

\section{A Triad GATs}

The residue numbering is based on the AS sequence. The conserved residues of the glutaminase site (Pro50, Gly58, Gly60, Cys85, Gln89, His172, Glu174) of different triad GATs have been superimposed on those of AS. The residues of the glutaminase site are shown in stick representation, colored in green (AS, PDB code 1I7Q), yellow (CPS, PDB code 1C3O), grey (CTPS, PDB code 1VCO), orange (FGAR-AT, PDB code 1T3T), pink (GMPS, PDB code 1GPM), cyan (PLPS, PDB code 2ISS). In this superposition, all enzymes are in complex with GIn or DON, except GMPS and PLPS. Indeed, for GMPS, only the unliganded structure has been reported and in the PLPS.GIn complex, glutamine is oriented differently in the glutaminase site. In triad GATs, the oxyanion hole is formed by one peptide nitrogen belonging to the residue immediately following the nucleophile cysteine and the second to an adjacent $\beta$-strand called the "oxyanion strand". The relative position of the residues of the catalytic triad (Cys85, His172, Glu174) and of the oxyanion hole (NH groups of Gly58 and Leu86) is conserved. The glutamine carboxylate is bound by the main-chain amides of Ser135 and Leu136 and by the side-chain amide of GIn89. The $\alpha$-amino group of glutamine is bound either by main-chain carbonyl groups or by oxygen atoms of an Asp/Glu residue. In the absence of a ligand at the glutaminase site, the residues in GMPS, potentially involved in binding the carboxylate and $\alpha$-amino groups of glutamine, are not in their competent binding conformation.

\section{B: Ntn GATs.}

The residue numbering is that of GImS. The $\mathrm{C} \alpha$ atoms of several conserved residues of the glutaminase site (Arg26, Arg73, Asn98, Gly99, Asp123) of different Ntn GATs in complex with glutamine or DON have been superimposed on those of GImS. The residues of the glutaminase site are shown in stick representation, colored in green (GImS, PDB code 2J6H, grey (E. coli GPAT, PDB code 1ECC), purple (B. subtilis 
GPAT, PDB code 1A0O), pink (Cys1Ala mutant of AsnB, PDB code 1CT9) or yellow (GItS, PDB code 1OFE). The hydrogen bond between the carbonyl oxygen atom of Cys 1 and the guanidinium group of Arg26 is conserved in all Ntn GATs. The sidechain carbonyl group of glutamine or DON is bound by the oxyanion hole formed by the backbone amide group of a conserved glycine residue and $\mathrm{N} \delta 2$ of a conserved asparagine residue. The carboxylate group of glutamine or DON forms a salt bridge with a conserved argine residue and its amino group makes $\mathrm{H}$-bonds with a conserved aspartate residue and with the carbonyl group of the glycine involved in the oxyanion hole. The Q-loop, which protects L-glutamine from bulk solvent is maintained in an open conformation in the structure of acceptor-bound Fd-GltS in complex with DON due to crystal packing constraints [24]. An oxygen atom of a residue belonging to the synthase domain (Thr606 in GImS, Glu1013 in GItS, Asp387 in GPAT) or a water molecule in AsnB and E. coli GPAT H-binds to the carboxylate group of glutamine or DON.

C: Activation of the glutaminase function upon acceptor binding.

Superposition of the glutaminase site of GPAT in complex with DON (in orange) [21], and in complex with DON and cPRPP (in white) [10]. In GPAT, the reorganization of the Q-loop (residues 73-84) upon acceptor binding to the DON-inactivated enzyme is accompanied by a reorientation of Arg73 in an optimal position to form a salt bridge with the carboxylate group of DON [10]. In addition, the carbonyl side-chain of Asp127 and the hydroxyl group of Thr76 are positioned to make hydrogen bonds to the amino group of the glutamine analog. These conformational changes likely explain the 110-fold lower glutamine $K_{m}$ for the glutaminase activity when the acceptor is present [21].

Fig. 2: Closing of the synthase site upon acceptor binding.

\section{A GImS}


Comparison of the synthase site structures of unliganded and acceptor-bound GImS (S Mouilleron et al., unpublished, [9••] shows the ordering of the C-terminal loop (residues 600-608, in magenta) upon sugar (yellow stick) binding to cover the synthase site.

B GPAT (top: GPAT in complex with DON (orange stick) [21], bottom: GPAT in complex with DON and cPRPP (grey stick) [10]. The binding of PRPP to the synthase domain results in three structural changes: a kinking of the synthase Cterminal helix (residues 471-492, in pink), an ordering of a synthase flexible loop (residues 326-350, in green), which closes the synthase site and participates in the channel formation, and a restructuring of the glutaminase Q-loop (residues 73-84, in blue), which covers the glutaminase site.

\section{PLPS}

The comparison of the synthase domain structures of PLPS from T. maritima in complex with acceptor R5P (in light blue) [31••] and that from B. subtilis in complex with glutamine (in dark blue) [30••] highlights the conformational changes that come with sugar binding. The residue numbering is that of $B$. subtilis. Upon R5P (green stick) binding, the synthase site closes mainly through translations of helix $\alpha 2$ ' (residues 48-55) and helix $3_{10}$ (residues 235-241) of more than $3 \AA$ towards the active site and the ordering of the C-terminal loop (residues 270-280, in magenta).

\section{FGAR-AT}

Comparison of the synthase domain structures of unliganded FGAR-AT from $S$. thyphimurium [22] and acceptor-bound synthase subunit from T. maritima [49•] shows the ordering of loop 186-207 (in magenta; T. maritima numbering) upon acceptor (green stick) binding to cover the synthase site.

\section{E AS}

Comparison of the synthase domain structures of unliganded S. solfataricus AS [26] and of S. marcescens AS in complex with the acceptor analog benzoate [45] reveals several conformational changes concomitant with the closure of the synthase site upon binding the chorismate acceptor substrate. Indeed, the relatively loose pocket 
of the synthase site in the unliganded structure has to narrow upon acceptor binding. Benzoate is shown in pink stick representation.

Fig. 3: Open and closed forms of channels

\section{A IGPS}

In IGPS, the core of a $(\beta \alpha)_{8}$ barrel is used for the transfer of ammonia between the glutaminase and synthase sites. The acceptor substrate PRFAR (green stick) binds at the top of the barrel and the acivicin glutamine analog (pink stick) is located at its bottom the interface between the glutaminase and synthase domains. A cyclic salt bridge formed by Arg239, Glu293, Lys360, Glu465 (yeast numbering, shown in stick representation) closes the bottom of the barrel.

B GImS

Trp74 acts as the gate of the channel in GImS (closed conformation as observed in the crystal structure of GImS in complex with fructose-6-P in yellow, open conformation as observed in the crystal structure of GImS in complex with DON and Fru6P in orange) [9••]. The accessible surface of the channel calculated with a probe radius of $1.4 \AA$ is represented as a mesh surface. The walls of the ammonia channel are constituted by Trp74 and Arg26 from the glutaminase domain, and by residues of the C-terminal loop of the synthase domain (orange coil).

C Fd-GltS

The channel of Fd-GltS is formed by residues of loop 4 (residues 968-1013) of the synthase domain, which interacts with the $\alpha$-amino terminal cysteine and is involved in the binding of the acceptor substrate. [23]. The accessible surface of the channel calculated with a probe radius of $1.4 \AA$ is represented as a mesh surface. Unfortunately, in the structure in complex with DON and acceptor substrate (DON in pink stick, $20 \mathrm{O}$ in green stick, FMN in cyan stick), the channel is obstructed both at the entrance (by Ser1011 and Ile1012 of loop4, and by Thr503 and Asn504 of the central domain) and near the acceptor by Glu903 and Lys966 because crystal packing constraints hinder a conformational change of the Q-loop that is necessary 
to open the channel [24].

\section{CTPS}

His57 likely acts as the gate of the channel in E. coli CTPS because His57 adopts two conformations in E. coli CTPS, which correspond either to a closed or open ammonia channel [41]. The accessible surface of the channel calculated with a probe radius of $1.2 \AA$. A vestibule open to solvent in the glutaminase domain and a tubular exit channel in the synthase site define an apparent ammonia diffusion path. In the closed conformation, the His57 side chain (in red) blocks the channel exit and the narrowest part of the accessible surface of $0.8-1.2 \AA$ does not allow passage of ammonia. In the open conformation, the His57 side chain (in green) is located near to the potential UTP acceptor binding site. The constriction between these two parts of the channel and the two observed conformations of His57, belonging to loop 5258 that forms the rim of the synthase site cavity, suggests that the channel opens upon acceptor binding, the side chain of His57 acting as the gate of the channel.

\section{E Trp synthase}

Open and closed conformations of the indole channel of tryptophan synthase. The accessible surface of the open channel calculated with a probe radius of $1.7 \AA$ is represented as a mesh surface. The side-chain of $\beta$ Phe280 partially blocks the intramolecular indole channel in the presence of $\mathrm{Na}^{+}$(in green), but moves out of the channel and lines its surface in the presence of cesium or potassium ions (in cyan), thereby accounting for the effect of cations on enzyme activity [42].

\section{References}

1. Zalkin H, Smith JL: Enzymes utilizing glutamine as an amide donor. Adv. Enzymol. Relat. Areas Mol. Biol. 1998, 72:87-144.

2. Horiuchi KY, Harpel MR, Shen L, Luo Y, Rogers KC, Copeland RA: Mechanistic studies

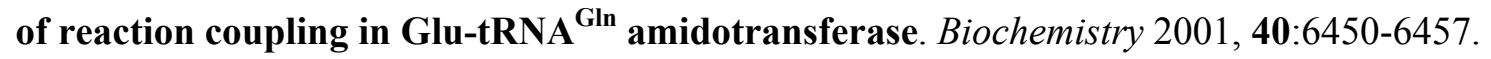
3. Feng L, Sheppard K, Tumbula-Hansen D, Soll D: Gln-tRNA ${ }^{\text {Gln }}$ formation from GlutRNA $^{\text {Gln }}$ requires cooperation of an asparaginase and a Glu-tRNA ${ }^{\text {Gln }}$ kinase. $J$ Biol Chem 
2005, 280:8150-8155.

4. Bieganowski P, Pace HC, Brenner C: Eukaryotic NAD ${ }^{+}$synthetase Qns1 contains an essential, obligate intramolecular thiol glutamine amidotransferase domain related to nitrilase. J Biol Chem 2003, 278:33049-33055.

5. Anderson KS: Fundamental mechanisms of substrate channeling. Methods Enzymol. 1999, 308:111-145.

6. Miles EW, Rhee S, Davies DR: The molecular basis of substrate channeling. $J$ Biol Chem 1999, 274:12193-12196.

7. Raushel FM, Thoden JB, Holden HM: The amidotransferase family of enzymes: molecular machines for the production and delivery of ammonia. Biochemistry 1999, 38:7891-7899.

8. Huang X, Holden HM, Raushel FM: Channeling of substrates and intermediates in enzyme-catalyzed reactions. Annu. Rev. Biochem. 2001, 70:149-180.

9••. Mouilleron S, Badet-Denisot M-A, Golinelli-Pimpaneau B: Glutamine binding opens the ammonia channel and activates glucosamine-6P synthase. J. Biol. Chem. 2006, 281:4404-4412.

The crystal structures of acceptor-bound GlmS with and without a glutamine affinity analog, respectively at $2.35 \AA$ and $2.05 \AA$ resolution, show that glutamine binding activates the enzyme through the closing of a loop to shield the glutaminase site, the positioning of several catalytic residues and the opening of the ammonia channel thanks to a rotation of the Trp74 indole group.

10. Krahn JM, Kim JH, Burns MR, Parry RJ, Zalkin H, Smith JL: Coupled formation of an amidotransferase interdomain ammonia channel and a phosphoribosyltransferase active site. Biochemistry 1997, 36:11061-11068.

11. Muchmore CR, Krahn JM, Kim JH, Zalkin H, Smith JL: Crystal structure of glutamine phosphoribosylpyrophosphate amidotransferase from Escherichia coli. Protein Sci 1998, 7:39-51.

12. Chaudhuri BN, Lange SC, Myers RS, Davisson VJ, Smith JL: Toward understanding the mechanism of the complex cyclization reaction catalyzed by imidazole 
glycerolphosphate synthase: crystal structures of a ternary complex and the free enzyme. Biochemistry 2003, 42:7003-7012.

13. Douangamath A, Walker M, Beismann-Driemeyer S, Vega-Fernandez MC, Sterner R, Wilmanns M: Structural evidence for ammonia tunneling across the (beta alpha)(8) barrel of the imidazole glycerol phosphate synthase bienzyme complex. Structure 2002, 10:185-193.

14•. Oshikane H, Sheppard K, Fukai S, Nakamura Y, Ishitani R, Numata T, Sherrer RL, Feng L, Schmitt E, Panvert M, et al.: Structural basis of RNA-dependent recruitment of glutamine to the genetic code. Science 2006, 312:1950-1954.

The crystal structure of GatDE from Methanothermobacter thermautotrophicus in complex with tRNA ${ }^{\text {Gln }}$ at $3.1 \AA$ resolution shows that specific recognition of Glu-tRNA ${ }^{\text {Gln }}$ by GatDE is achieved by the enfolding of the acceptor-T $\Psi$ helix of tRNA, and by shape complementarity with its T $\Psi$ arm and D-loop. Moreover, the use of tRNA mutants indicates that the A1-U72 base pair in tRNA ${ }^{\mathrm{Gln}}$ is important for recognition by GatDE. An explanation for the specificity of GatDE for Glu-tRNA ${ }^{\text {Gln }}$ in contrast to bacterial GatCABs, which act as both Glu- and AspGATs, is proposed: the AspRS-like insertion synthetase domain, which is present in GatDE but not in GatCAB, could facilitate the formation of a GluRS/GatDE complex, while preventing association with AspRS. This complex would channel only the mysacylated GlutRNA $^{\text {Gln }}$ between the GluRS and GatDE enzymes.

15. Schmitt E, Panvert M, Blanquet S, Mechulam Y: Structural basis for tRNA-dependent amidotransferase function. Structure 2005, 13:1421-1433.

16•. Nakamura A, Yao M, Chimnaronk S, Sakai N, Tanaka I: Ammonia channel couples glutaminase with transamidase reactions in GatCAB. Science 2006, 312:1954-1958.

The crystal structures of GatCAB from Staphylococcus aureus alone and in complex with glutamine, asparagines, ATP analog or $\mathrm{Mn}^{2+}$ are reported. Discrimination between GlutRNA $^{\text {Gln }}$ and Glu-tRNA ${ }^{\text {Glu }}$ by GatCAB is shown to be achieved by specific recognition of the U1-A72 base pair whereas the insertion of a $U$ in the D-loop of tRNA serves as a negative determinant.

17. Larsen TM, Boehlein SK, Schuster SM, Richards NG, Thoden JB, Holden HM, Rayment 
I: Three-dimensional structure of Escherichia coli asparagine synthetase B: a short journey from substrate to product. Biochemistry 1999, 38:16146-16157.

18. Tesmer JJ, Klem TJ, Deras ML, Davisson VJ, Smith JL: The crystal structure of GMP synthetase reveals a novel catalytic triad and is a structural paradigm for two enzyme families. Nat Struct Biol 1996, 3:74-86.

19. Goto M, Omi R, Nakagawa N, Miyahara I, Hirotsu K: Crystal structures of CTP synthetase reveal ATP, UTP, and glutamine binding sites. Structure 2004, 12:1413-1423.

20. Morollo AA, Eck MJ: Structure of the cooperative allosteric anthranilate synthase from Salmonella typhimurium. Nat Struct Biol 2001, 8:243-247.

21. Kim JH, Krahn JM, Tomchick DR, Smith JL, Zalkin H: Structure and function of the glutamine phosphoribosylpyrophosphate amidotransferase glutamine site and communication with the phosphoribosylpyrophosphate site. J Biol Chem 1996, 271:15549-15557.

22. Anand R, Hoskins AA, Stubbe J, Ealick SE: Domain organization of Salmonella typhimurium formylglycinamide ribonucleotide amidotransferase revealed by X-ray crystallography. Biochemistry 2004, 43:10328-10342.

23. Van den Heuvel RH, Curti B, Vanoni MA, Mattevi A: Glutamate synthase: a fascinating pathway from L-glutamine to L-glutamate. Cell. Mol. Life Sci. 2004, 61:669681.

24. Van den Heuvel RH, Svergun DI, Petoukhov MV, Coda A, Curti B, Ravasio S, Vanoni MA, Mattevi A: The active conformation of glutamate synthase and its binding to ferredoxin. J. Mol. Biol. 2003, 330:113-128.

25. Chaudhuri BN, Lange SC, Myers RS, Chittur SV, Davisson VJ, Smith JL: Crystal structure of imidazole glycerol phosphate synthase: a tunnel through a (beta/alpha)8 barrel joins two active sites. Structure (Camb) 2001, 9:987-997.

26. Knochel T, Ivens A, Hester G, Gonzalez A, Bauerle R, Wilmanns M, Kirschner K, Jansonius JN: The crystal structure of anthranilate synthase from Sulfolobus solfataricus: functional implications. Proc Natl Acad Sci U S A 1999, 96:9479-9484.

27. Dossena L, Curti B, Vanoni MA: Activation and coupling of the glutaminase and 
synthase reaction of glutamate synthase is mediated by E1013 of the ferredoxindependent enzyme, belonging to loop 4 of the synthase domain. Biochemistry 2007, 46:4473-4485.

28. Myers RS, Jensen JR, Deras IL, Smith JL, Davisson VJ: Substrate-induced changes in the ammonia channel for imidazole glycerol phosphate synthase. Biochemistry 2003, 42:7013-7022.

29•. Mouilleron S, Golinelli-Pimpaneau B: Domain motions of glucosamine-6P synthase: comparison of the anisotropic displacements in the crystals and the catalytic hingebending rotation. Protein Sci 2007, 16:485-493.

The analysis of the anisotropic domain displacements observed in the crystals of GlmS in complex with acceptor, and in complex with both acceptor and glutamine affinity analog, suggests that the intramolecular mobility of the sugar-bound enzyme contributes to facilitate the domain motion that occurs upon glutamine binding during catalysis.

30••. Strohmeier M, Raschle T, Mazurkiewicz J, Rippe K, Sinning I, Fitzpatrick TB, Tews I: Structure of a bacterial pyridoxal 5'-phosphate synthase complex. Proc Natl Acad Sci U S A 2006, 103:19284-19289.

The structure of PLP synthase from Bacillus subtilis in complex with glutamine at $2.1 \AA$ resolution as well as those of the individual glutaminase and synthase subunits are reported. The complex consists of a core of twelve synthase monomers with twelve noninteracting glutaminase subunits attached to the core. Comparison of the different structures shows the structural changes occurring upon complex formation.

31••. Zein F, Zhang Y, Kang YN, Burns K, Begley TP, Ealick SE: Structural insights into the mechanism of the PLP synthase holoenzyme from Thermotoga maritima. Biochemistry 2006, 45:14609-14620.

The structure of PLP synthase from Thermotoga maritima at $2.9 \AA$ resolution reveals that the complex consists of a core of twelve synthase monomers with twelve noninteracting glutaminase subunits attached to the core. The acceptor substrate, ribulose-5-P, is bound via an imine bond to the synthase site, which allows the authors to propose a mechanism for the reaction. 
32. Zhu J, Burgner JW, Harms E, Belitsky BR, Smith JL: A new arrangement of (beta/alpha)8 barrels in the synthase subunit of PLP synthase. J Biol Chem 2005, 280:27914-27923.

33. Bauer JA, Bennett EM, Begley TP, Ealick SE: Three-dimensional structure of YaaE from Bacillus subtilis, a glutaminase implicated in pyridoxal-5'-phosphate biosynthesis. $J$ Biol Chem 2004, 279:2704-2711.

34. Gengenbacher M, Fitzpatrick TB, Raschle T, Flicker K, Sinning I, Muller S, Macheroux P, Tews I, Kappes B: Vitamin B6 biosynthesis by the malaria parasite Plasmodium falciparum: biochemical and structural insights. J Biol Chem 2006, 281:3633-3641.

35. Isupov MN, Obmolova G, Butterworth S, Badet-Denisot MA, Badet B, Polikarpov I, Littlechild JA, Teplyakov A: Substrate binding is required for assembly of the active conformation of the catalytic site in Ntn amidotransferases: evidence from the $1.8 \mathrm{~A}$ crystal structure of the glutaminase domain of glucosamine 6-phosphate synthase. Structure 1996, 4:801-810.

36. Korolev S, Skarina T, Evdokimova E, Beasley S, Edwards A, Joachimiak A, Savchenko A: Crystal structure of glutamine amidotransferase from Thermotoga maritima. Proteins 2002, 49:420-422.

37. Myers RS, Amaro RE, Luthey-Schulten ZA, Davisson VJ: Reaction coupling through interdomain contacts in imidazole glycerol phosphate synthase. Biochemistry 2005, 44:11974-11985.

38. Thoden JB, Holden HM, Wesenberg G, Raushel FM, Rayment I: Structure of carbamoyl phosphate synthetase: a journey of 96 A from substrate to product. Biochemistry 1997, 36:6305-6316.

39. Beismann-Driemeyer S, Sterner R: Imidazole glycerol phosphate synthase from Thermotoga maritima. Quaternary structure, steady-state kinetics, and reaction mechanism of the bienzyme complex. J Biol Chem 2001, 276:20387-20396.

40. Omi R, Mizuguchi H, Goto M, Miyahara I, Hayashi H, Kagamiyama H, Hirotsu K: Structure of imidazole glycerol phosphate synthase from Thermus thermophilus HB8: open-closed conformational change and ammonia tunneling. J Biochem (Tokyo) 2002, 
132:759-765.

41. Endrizzi JA, Kim H, Anderson PM, Baldwin EP: Crystal structure of Escherichia coli cytidine triphosphate synthetase, a nucleotide-regulated glutamine amidotransferase/ATP-dependent amidoligase fusion protein and homologue of anticancer and antiparasitic drug targets. Biochemistry 2004, 43:6447-6463.

42. Rhee S, Parris KD, Ahmed SA, Miles EW, Davies DR: Exchange of $\mathrm{K}^{+}$or $\mathrm{Cs}^{+}$for $\mathrm{Na}^{+}$ induces local and long-range changes in the three-dimensional structure of the tryptophan synthase alpha2beta2 complex. Biochemistry 1996, 35:4211-4221.

43. Thoden JB, Raushel FM, Benning MM, Rayment I, Holden HM: The structure of carbamoyl phosphate synthetase determined to 2.1 A resolution. Acta Crystallogr D Biol Crystallogr 1999, 55 ( Pt 1):8-24.

44. Thoden JB, Huang X, Raushel FM, Holden HM: The small subunit of carbamoyl phosphate synthetase: snapshots along the reaction pathway. Biochemistry 1999, 38:16158-16166.

45. Spraggon G, Kim C, Nguyen-Huu X, Yee MC, Yanofsky C, Mills SE: The structures of anthranilate synthase of Serratia marcescens crystallized in the presence of (i) its substrates, chorismate and glutamine, and a product, glutamate, and (ii) its end-product inhibitor, L-tryptophan. Proc Natl Acad Sci U S A 2001, 98:6021-6026.

46. Thoden JB, Wesenberg G, Raushel FM, Holden HM: Carbamoyl phosphate synthetase: closure of the B-domain as a result of nucleotide binding. Biochemistry 1999, 38:23472357.

47. van den Heuvel RH, Ferrari D, Bossi RT, Ravasio S, Curti B, Vanoni MA, Florencio FJ, Mattevi A: Structural studies on the synchronization of catalytic centers in glutamate synthase. J Biol Chem 2002, 277:24579-24583.

48. Chen S, Tomchick DR, Wolle D, Hu P, Smith JL, Switzer RL, Zalkin H: Mechanism of the synergistic end-product regulation of Bacillus subtilis glutamine phosphoribosylpyrophosphate amidotransferase by nucleotides. Biochemistry 1997, 36:10718-10726.

49•. Morar M, Anand R, Hoskins AA, Stubbe J, Ealick SE: Complexed structures of 
formylglycinamide ribonucleotide amidotransferase from Thermotoga maritima describe a novel ATP binding protein superfamily. Biochemistry 2006, 45:14880-14895.

Five different structures of the synthetase subunit of FGAR-AT from Thermotoga maritima have been determined in the presence of substrates, a substrate analog, and a product. The comparison of these structures to that of unliganded enzyme illuminate the conformational changes occurring upon acceptor and ATP binding to the synthase site. 
Figure 1

A
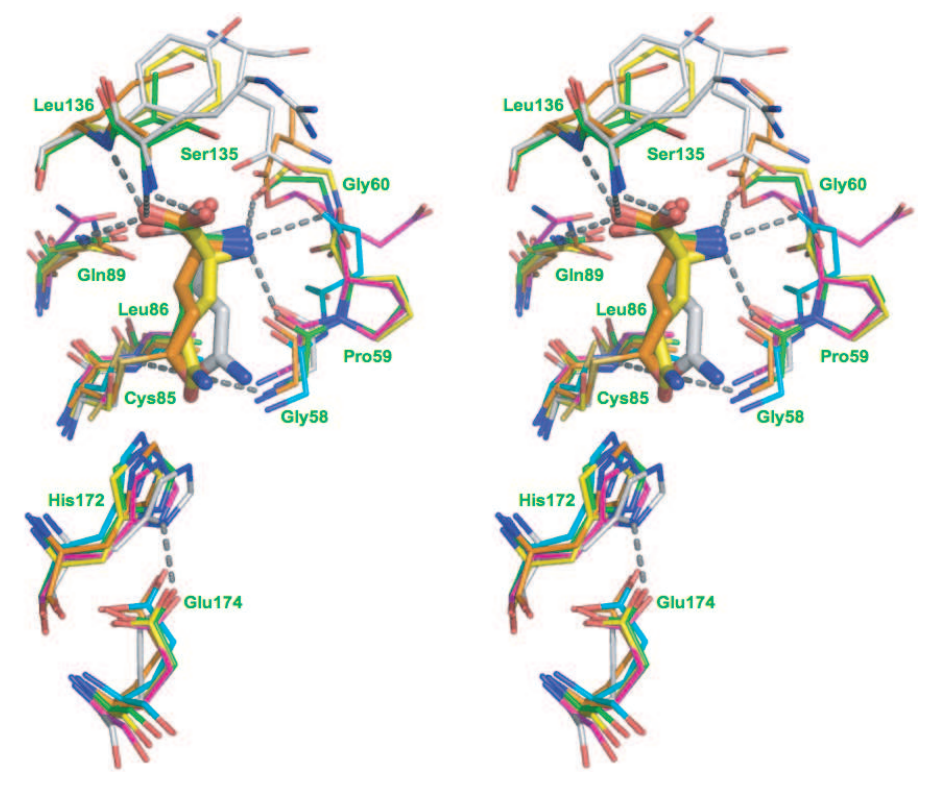

$$
\text { B }
$$
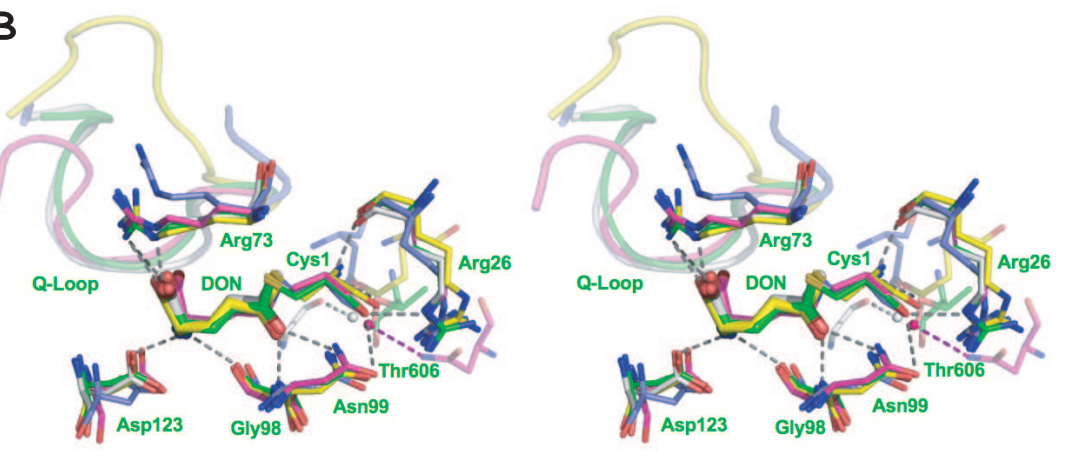

C

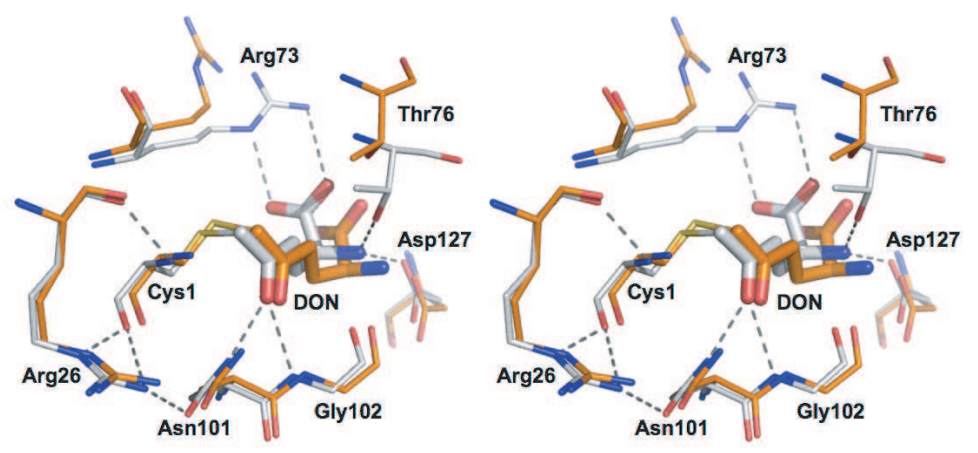


A
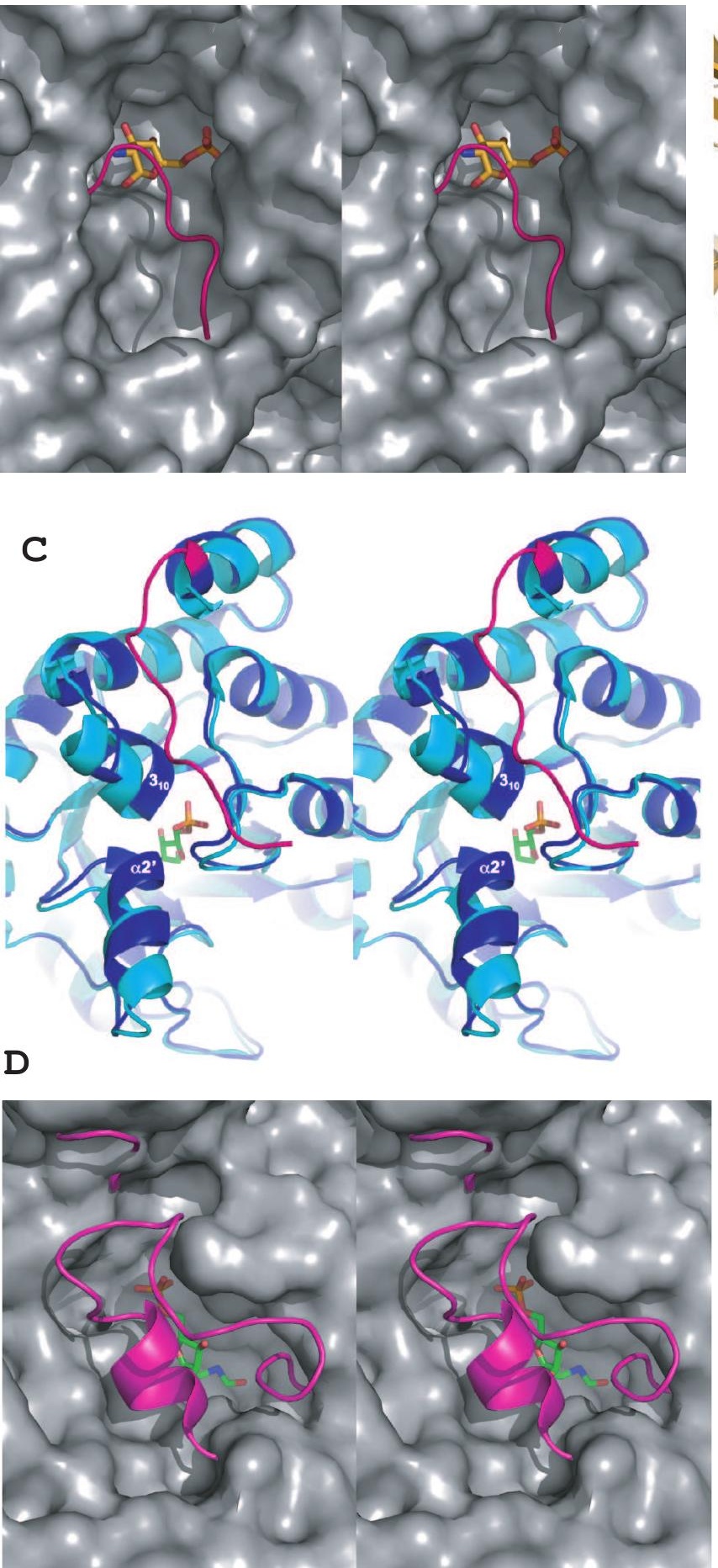

B
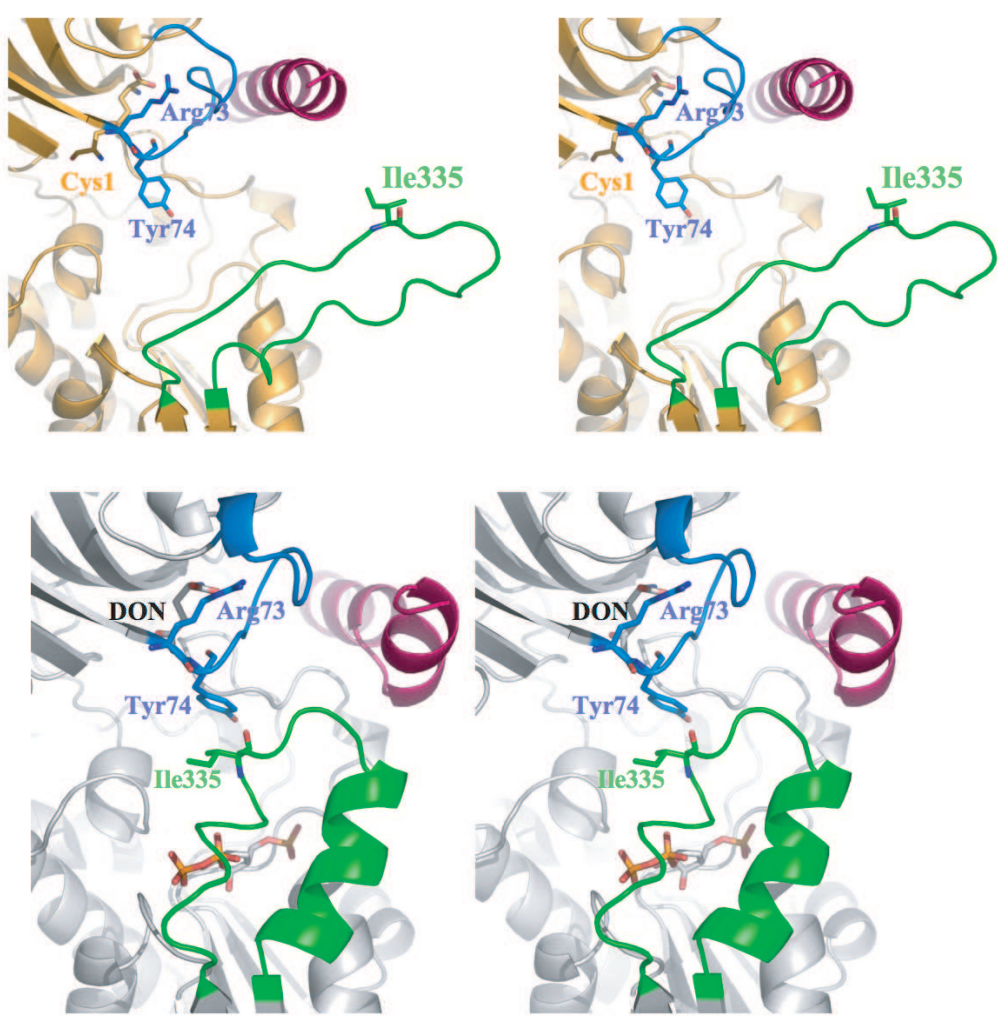

E
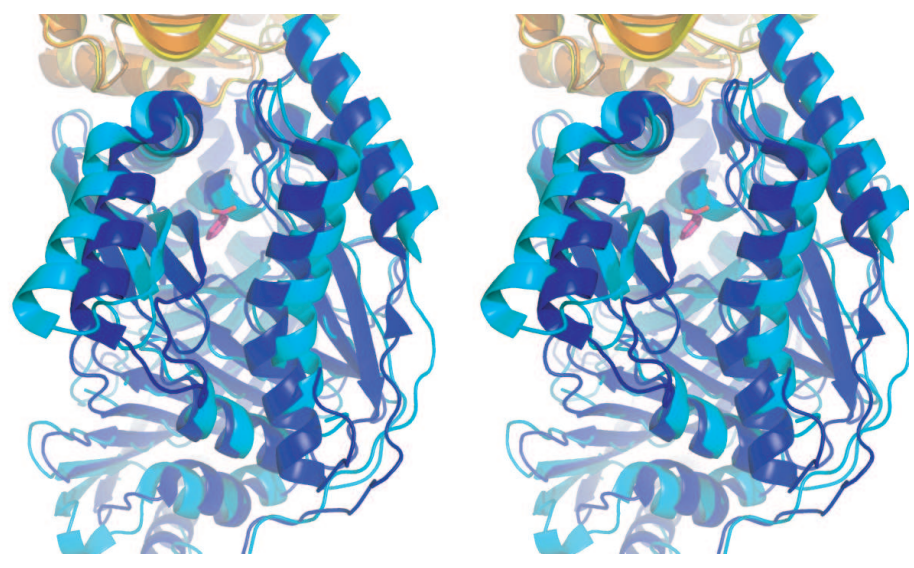
Table 1: Substrates and products of structurally-characterized GATs.

A) Triad GATs

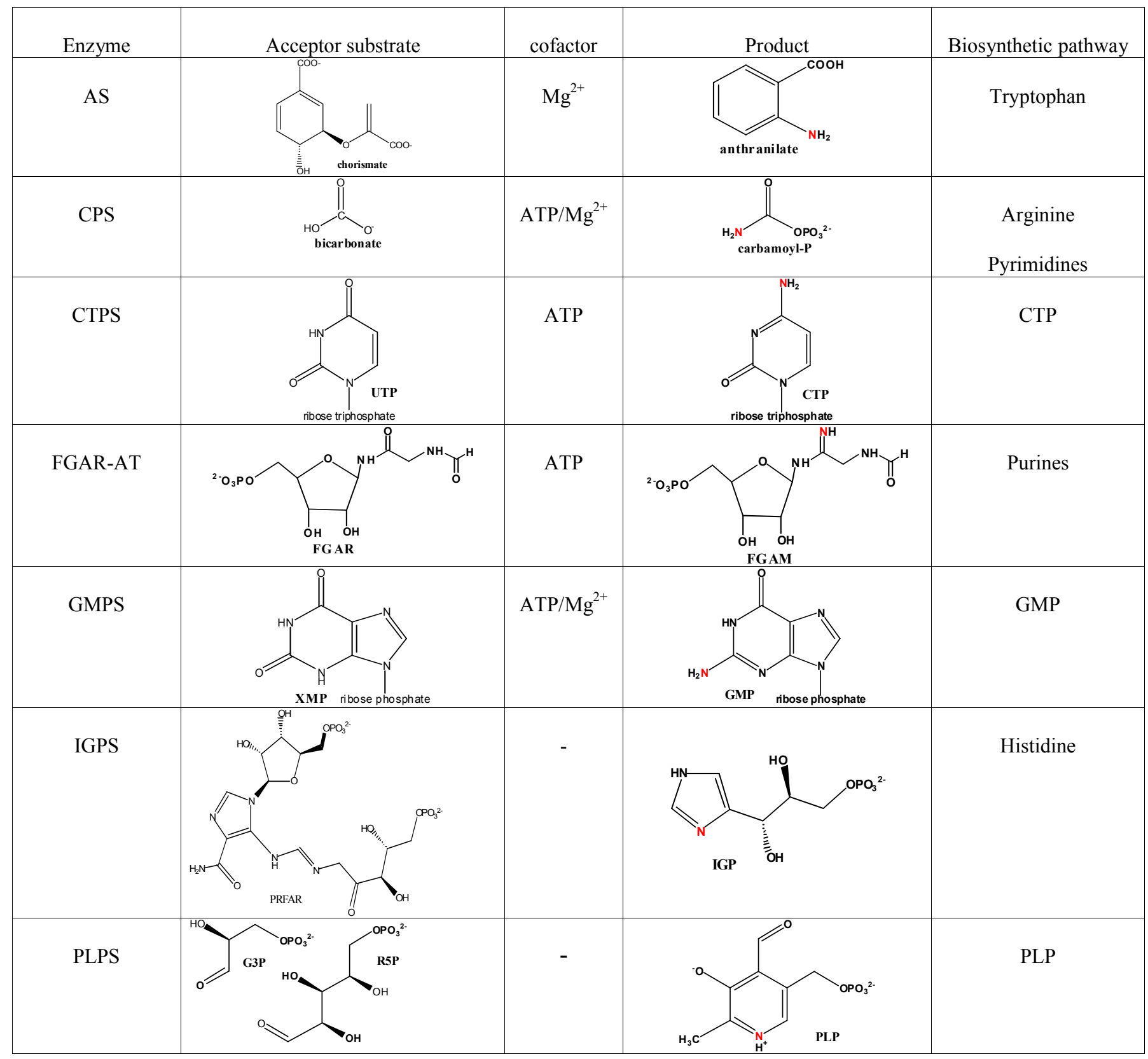




\section{B) Ntn GATs}

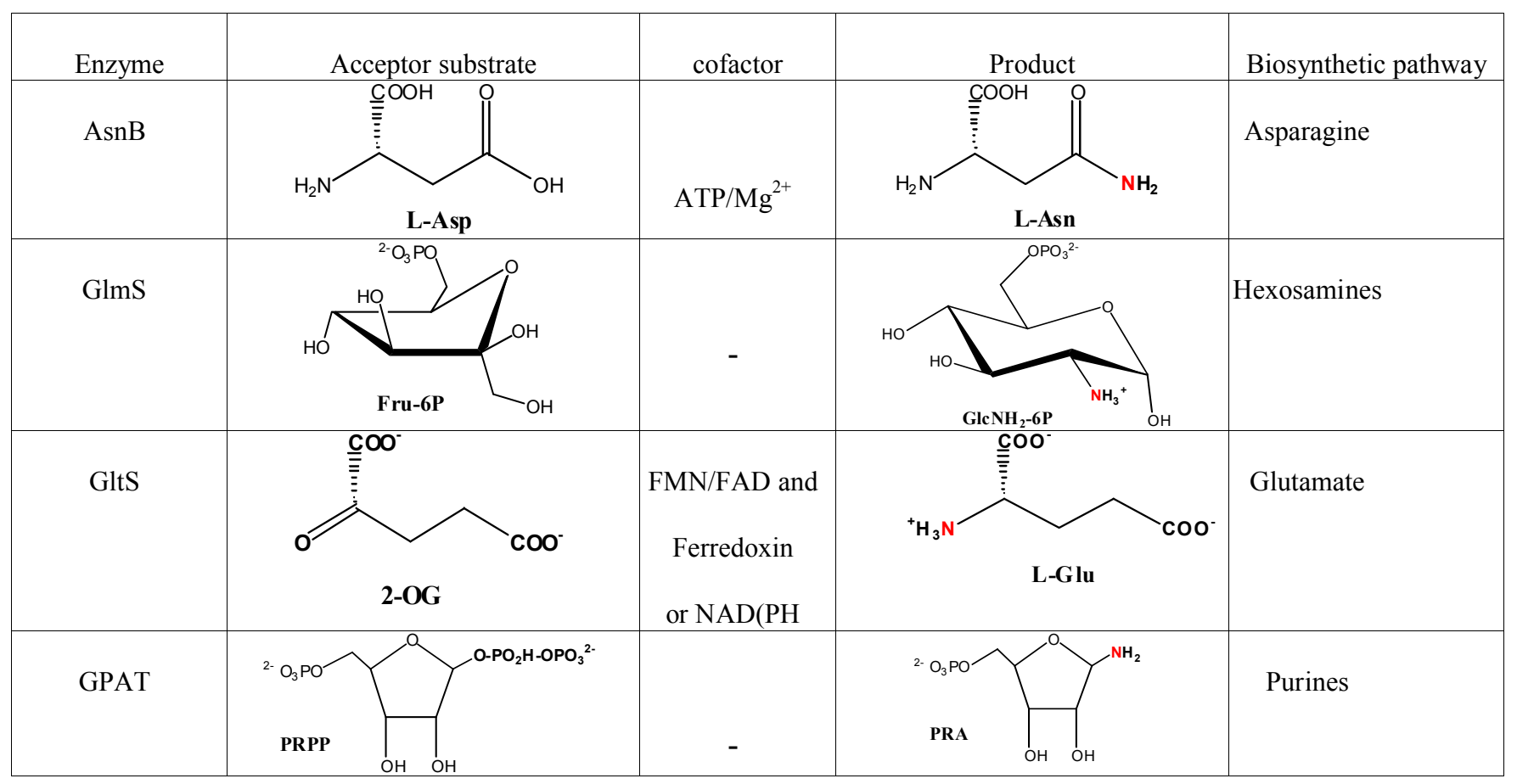

\section{C) Other class}

\begin{tabular}{|c|c|c|c|c|}
\hline Enzyme & Acceptor substrate & cofactor & Product & Biosynthetic pathway \\
\hline Glu-tRNA $^{\text {Gln }}$ AT* $^{2}$ & Glu-tRNA $^{\text {Gln }}$ & ATP & Gln-tRNA $^{\text {Gln }}$ & Gln-ARNt $^{\text {Gln }}$ \\
\hline
\end{tabular}

* Ammonia production is achieved by the structurally different bacterial GatA or archeal GatD subunits, that do not share obvious sequence relationship with class I or class II amidotransferases. GatA and GatD belong to the glutaminase superfamily, GatA being similar to amidases [2] and GatD to L-asparaginases [3]. 
Table 2: Main cristallographic structures of GATs.

A Triad GATs

\begin{tabular}{|c|c|c|c|c|}
\hline Enzyme & PDB code & $\begin{array}{l}\text { Ligand in } \\
\text { the synthase } \\
\text { domain }\end{array}$ & $\begin{array}{l}\text { Ligand at } \\
\text { the } \\
\text { glutaminase } \\
\text { site }\end{array}$ & Form \\
\hline $\begin{array}{c}\text { AS } \\
\text { Sulfolobus solfataricus }\end{array}$ & 1QDL [26] & - & - & $\mathrm{i}$ \\
\hline $\begin{array}{c}\text { AS } \\
\text { Serratia marcescens }\end{array}$ & 1I7Q [45] & benzoate & $\begin{array}{c}\text { Glutamyl- } \\
\text { thioester }\end{array}$ & $*$ \\
\hline $\begin{array}{c}\text { AS } \\
\text { Serratia marcescens }\end{array}$ & $1 \mathrm{I} 7 \mathrm{~S}[45]$ & Tryptophan $^{1}$ & - & $*$ \\
\hline $\begin{array}{c}\text { AS } \\
\text { Salmonella typhimurium }\end{array}$ & 1I1Q [20] & Tryptophan $^{1}$ & & \\
\hline $\begin{array}{c}\text { CPS } \\
\text { Escherichia coli }\end{array}$ & 1BXR [46] & $\begin{array}{l}\text { Ornithine }^{2} / \\
\text { AMPPNP }\end{array}$ & - & ii \\
\hline $\begin{array}{l}\text { CPS (mutant C269S) } \\
\text { Escherichia coli }\end{array}$ & $1 \mathrm{C} 3 \mathrm{O}[44]$ & $\begin{array}{l}\text { Ornithine }^{2} / \\
\text { ADP }\end{array}$ & Gln & iii \\
\hline $\begin{array}{c}\text { CTPS } \\
\text { Thermus thermophilus }\end{array}$ & 1VCM [19] & - & - & $\mathrm{i}$ \\
\hline $\begin{array}{c}\text { CTPS } \\
\text { Thermus thermophilus }\end{array}$ & 1VCO [19] & - & Gln & $*$ \\
\hline $\begin{array}{c}\text { CTPS } \\
\text { Escherichia coli }\end{array}$ & 1S1M [41] & - & - & $\mathrm{i}$ \\
\hline $\begin{array}{c}\text { FGAR-AT } \\
\text { Salmonella typhimurium }\end{array}$ & 1T3T [22] & - & $\begin{array}{l}\text { Glutamyl- } \\
\text { thioester }\end{array}$ & ii \\
\hline $\begin{array}{c}\text { GMPS } \\
\text { Escherichia coli }\end{array}$ & 1GPM [18] & AMP, PPi & - & $\mathrm{i}$ \\
\hline $\begin{array}{c}\text { IGPS } \\
\text { Thermotoga maritima }\end{array}$ & 1GPW [13] & - & - & $\mathrm{i}$ \\
\hline $\begin{array}{c}\text { IGPS } \\
\text { Thermus thermophilus }\end{array}$ & 1KA9 [40] & - & - & $\mathrm{i}$ \\
\hline yeast IGPS & 10X6 [12] & - & - & $\mathrm{i}$ \\
\hline yeast IGPS & $1 \mathrm{JVN}$ [25] & - & acivicin & \\
\hline yeast IGPS & $1 \mathrm{OX} 4$ [12] & - & DON & \\
\hline yeast IGPS & 1OX5 [12] & PRFAR & acivicin & $\mathrm{iii}^{3}$ \\
\hline $\begin{array}{c}\text { PLPS } \\
\text { Bacillus subtilis }\end{array}$ & $2 \mathrm{NV} 2[30 \bullet \bullet]$ & - & Gln & \\
\hline $\begin{array}{c}\text { PLPS } \\
\text { Thermotoga maritima }\end{array}$ & 2ISS $[31 \bullet \bullet]$ & $\mathrm{R} 5 \mathrm{P}$ & - & ii \\
\hline
\end{tabular}


B Ntn GATs

\begin{tabular}{|c|c|c|c|c|}
\hline Enzyme & PDB code & $\begin{array}{c}\text { Acceptor in } \\
\text { the synthase } \\
\text { domain }\end{array}$ & $\begin{array}{l}\text { Ligand at } \\
\text { the } \\
\text { glutaminase } \\
\text { site }\end{array}$ & Form \\
\hline $\begin{array}{c}\text { AsnB (mutant C1A) } \\
\text { Escherichia coli }\end{array}$ & 1CT9 [17] & - & Gln & $*$ \\
\hline $\begin{array}{c}\text { GlmS } \\
\text { Escherichia coli }\end{array}$ & 2BPL $[9 \bullet \bullet]$ & Fru6P & - & ii \\
\hline $\begin{array}{c}\text { GlmS } \\
\text { Escherichia coli }\end{array}$ & 2J6H $[9 \bullet \bullet]$ & Glucose-6P & $\mathrm{DON}$ & iii \\
\hline $\begin{array}{c}\text { GltS } \\
\text { Synechocystis sp. }\end{array}$ & 1LM1 [47] & - & - & $\mathrm{i}$ \\
\hline $\begin{array}{c}\text { GltS } \\
\text { Synechocystis sp. }\end{array}$ & 1OFD [24] & $2 \mathrm{OG}$ & - & ii \\
\hline $\begin{array}{c}\text { GltS } \\
\text { Synechocystis sp. }\end{array}$ & 1OFE [24] & $2 \mathrm{OG}$ & DON & $\mathrm{iii}^{4}$ \\
\hline $\begin{array}{c}\text { GPAT } \\
\text { Bacillus subtilis }\end{array}$ & $1 \mathrm{AO} 0[48]$ & ADP/GMP & - & \\
\hline $\begin{array}{c}\text { GPAT } \\
\text { Escherichia coli }\end{array}$ & 1ECG [21] & - & $\mathrm{DON}$ & $*$ \\
\hline $\begin{array}{c}\text { GPAT } \\
\text { Escherichia. coli }\end{array}$ & $1 \mathrm{ECC}[10]$ & c-PRPP & DON & iii \\
\hline
\end{tabular}

\section{Other class}

\begin{tabular}{|c|c|c|c|c|}
\hline $\begin{array}{c}\text { GatCAB } \\
\text { Staphylococcus aureus }\end{array}$ & $2 \mathrm{G} 5 \mathrm{H}[16 \bullet]$ & - & - & $\mathrm{i}$ \\
\hline $\begin{array}{c}\text { GatCAB } \\
\text { Staphylococcus aureus }\end{array}$ & 2DF4 [16•] & ATP analog & & $\mathrm{i}$ \\
\hline $\begin{array}{c}\text { GatCAB } \\
\text { Staphylococcus aureus }\end{array}$ & $2 \mathrm{~F} 2 \mathrm{~A}[16 \bullet]$ & - & Gln & \\
\hline $\begin{array}{c}\text { GatDE } \\
\text { Pyrococcus abyssi }\end{array}$ & 1ZQ1 [15] & - & - & $\mathrm{i}$ \\
\hline $\begin{array}{c}\text { GatDE } \\
\text { Methanothermobacter } \\
\text { thermautotrophicus }\end{array}$ & $2 \mathrm{D} 6 \mathrm{~F}[14 \bullet]$ & $\mathrm{tRNA}^{\mathrm{Gln}}$ & - & ii \\
\hline
\end{tabular}

(i): acceptor- and glutamine-free state

(ii): acceptor-bound state

(iii): glutamine and acceptor-bound state

*: not catalytically competent 
Supplementary Table 1: Activation of the glutaminase function of several structurally characterized GATs upon acceptor (and cofactor) binding.

\begin{tabular}{|c|c|c|c|}
\hline Enzyme & Type of kinetics & $\begin{array}{c}\text { Factor of glutaminase } \\
\text { activation } \\
\left(\mathrm{k}_{\mathrm{cat}}^{\left.+{ }^{+a c c} / \mathrm{k}_{\mathrm{cat}}{ }^{-\mathrm{acc}}\right)}\right.\end{array}$ & $\begin{array}{c}\text { Stimulation of } \\
\text { glutaminases inhibition } \\
\text { by glutamine analog } \\
\left(\mathrm{k}_{\text {inaat }}+\text { acc } / \mathrm{k}_{\text {inacat }}{ }^{-\mathrm{ccc}}\right)\end{array}$ \\
\hline AS S. typhimurium & $\begin{array}{l}\text { Ordered:acceptor binds } \\
\text { first [1] }\end{array}$ & $5[1]$ & $36[1]$ \\
\hline AS S. marcescens & & $7[2]$ & $23[2]$ \\
\hline CPS E. coli & & 275 [3] & \\
\hline CTPS E. coli & & $6[4]$ & 19 [5] \\
\hline GMPS E. coli & & & 21 [6] \\
\hline Fd-GltS Synechocystis sp. & & $\mathrm{b}_{[7]}$ & \\
\hline GlmS E. coli & $\begin{array}{c}\text { bi bi ordered: } \\
\text { Acceptor binds first [8] }\end{array}$ & 103 [9] & \\
\hline GPAT E. coli & & $22[10]$ & 14 [11] \\
\hline IGPS E. coli & & $125[12]$ & \\
\hline yeast IGPS & Random sequential [13] & $1240[14]$ & \\
\hline PLPS B. subtilis & & No activation $^{\mathrm{C}}[15]$ & \\
\hline $\begin{array}{c}\text { GatDE } \\
\text { M.thermautotrophicus }\end{array}$ & & $\mathrm{b}_{[16]}$ & \\
\hline
\end{tabular}

a: The $k_{\text {cat }}$ and $k_{\text {inact }}$ values are determined in the presence $\left({ }^{+a c c}\right)$ or in the absence $\left({ }^{-a c c}\right)$ of the acceptor and cofactor.

${ }^{\mathrm{b}}$ : No glutaminase activity in the absence of acceptor and cofactor.

c: In PLPS, the acceptor domain appears to be sufficient to stimulate the glutaminase activity since the addition of substrates to the synthase domain does not enhance the rate of glutamine hydrolysis. However, since the PLP activity observed was sub-optimal, a detailed analysis to confirm this point is needed. 
Supplementary Fig. 1: Hinge domain movements in GATs

A GlmS

Comparison of the acceptor-bound GlmS structure (synthase domain in blue, glutaminase domain in orange) and the structure in complex with both acceptor and glutamine analog (synthase domain in cyan, glutaminase domain in yellow) reveals a $23^{\circ}$ hinge motion of the glutamine domain relative to the synthase domain upon glutamine binding [17]. The Fru6P acceptor is shown in cyan stick and DON in pink stick.

\section{B CTPS}

Comparison of the unliganded (synthase domain in cyan, glutaminase domain in yellow) and sulfate-bound (synthase domain in blue, glutaminase domain in orange) structures of $T$. thermophilus CTPS [18]. The sulfate ions and the catalytic triad are shown in stick representation. Upon binding of sulfate ions, a hinging rotation of the glutaminase domain toward the synthase domain of $3.6^{\circ}$ occurs, indicating mobility of the glutaminase domain relative to the synthase domain. This motion may sketch out the conformational change of the enzyme expected to occur upon binding ATP and UTP acceptor substrate, since the sulfates are assumed to be located at positions specific for the UTP and ATP phosphates.

C IGPS

The unliganded heterodimeric T. maritima IGPS (synthase domain in blue, glutaminase domain in orange) [19] has a more open surface between the catalytic domains than the acivicin- PRFAR-bound yeast enzyme (synthase domain in cyan, glutaminase domain in yellow) [20]. The T. thermophilus unliganded IGPS structure [21] has an intermediate hinge position. The glutamine analog acivicin is shown in pink stick, the acceptor substrate PRFAR in green stick and the catalytic triad in yellow stick. The residue numbering corresponds to the yeast enzyme. Opening of the interdomain hinge eliminates two contacts between the synthase domain and the 
glutaminase active site that occur in the yeast enzyme: the $\mathrm{H}$-bond between Gln397 of the synthase domain to the glutamine analog in the glutaminase site and the backbone $\mathrm{H}$-bond between Ala393 of the synthase domain and Asn52 belonging to the oxyanion strand in the glutaminase site. By contrast, the salt bridge between Asp359 from the synthase domain and Lys196, a residue belonging to the glutaminase loop that contains the His and Glu catalytic residues, which anchors the interface in this region and stabilizes the glutaminase active site structure, is not affected by the hinge motion. The occurence of a large scale hinge-closing motion upon PRFAR binding is supported by steered molecular dynamics simulations of the undocking of PRFAR in IGPS [22].

Supplementary Fig. 2: Comparison of the putative channel in PLPS from $B$. subtilis and $T$. maritima.

In PLPS from T. maritima (synthase domain in dark blue, glutaminase domain in orange) [23] and from B. subtilis (synthase domain in light blue, glutaminase domain in yellow) [24], no obvious channel links the glutaminase and synthase sites. A putative channel has been proposed, which would be lined by the $\mathrm{N}$-terminal $\alpha$-helix of the synthase subunit (residues 7 to 17) and several hydrophobic residues (Met43, Met79, Val126, Met145, Phe210, Phe 233) that need to move to connect the two active sites. The residue numbering is that of $B$. subtilis PLPS.

\section{References}

1. Nagano H, Zalkin H: Some physicochemical properties of anthranilate synthetase component I from Salmonella typhimurium. J Biol Chem 1970, 245:3097-3103.

2. Zalkin H, Hwang LH: Anthranilate Synthetase from Serratia marcescens. On the properties and relationship to the enzyme from Salmonella typhimurium. J Biol Chem 1971, 246:6899-6907.

3. Miles BW, Raushel FM: Synchronization of the three reaction centers within carbamoyl phosphate synthetase. Biochemistry 2000, 39:5051-5056.

4. Koshland DEJ, Levitzki A: CTP synthetase and related enzymes. In The Enzymes. Edited by Boyer P: Academic Press; 1974:539-559. vol 10.]

5. Levitzki A, Stallcup WB, Koshland DE, Jr.: Half-of-the-sites reactivity and the 
conformational states of cytidine triphosphate synthetase. Biochemistry 1971, 10:33713378.

6. Zalkin H, Truitt CD: Characterization of the glutamine site of Escherichia coli guanosine 5'-monophosphate synthetase. J Biol Chem 1977, 252:5431-5436.

7. Ravasio S, Dossena L, Martin-Figueroa E, Florencio FJ, Mattevi A, Morandi P, Curti B,

Vanoni MA: Properties of the recombinant ferredoxin-dependent glutamate synthase of Synechocystis PCC6803. Comparison with the Azospirillum brasilense NADPHdependent enzyme and its isolated alpha subunit. Biochemistry 2002, 41:8120-8133. 8. Badet B, Vermoote P, Le Goffic F: Glucosamine synthetase from Escherichia coli: kinetic mechanism and inhibition by N3-fumaroyl-L-2,3-diaminopropionic derivatives. Biochemistry 1988, 27:2282-2287.

9. Floquet N, Mouilleron S, Daher R, Maigret B, Badet B, Badet-Denisot MA: Ammonia channeling in bacterial glucosamine-6-phosphate synthase (GIms): Molecular dynamics simulations and kinetic studies of protein mutants. FEBS Lett 2007, 581:29812987.

10. Messenger LJ, Zalkin H: Glutamine phosphoribosylpyrophosphate amidotransferase from Escherichia coli. Purification and properties. J Biol Chem 1979, 254:3382-3392.

11. Hartman SC: The Interaction of 6-Diazo-5-Oxo-L-Norleucine with Phosphoribosyl Pyrophosphate Amidotransferase. J Biol Chem 1963, 238:3036-3047.

12. Klem TJ, Davisson VJ: Imidazole glycerol phosphate synthase: the glutamine amidotransferase in histidine biosynthesis. Biochemistry 1993, 32:5177-5186.

13. Myers RS, Jensen JR, Deras IL, Smith JL, Davisson VJ: Substrate-induced changes in the ammonia channel for imidazole glycerol phosphate synthase. Biochemistry 2003, 42:7013-7022.

14. Myers RS, Amaro RE, Luthey-Schulten ZA, Davisson VJ: Reaction coupling through interdomain contacts in imidazole glycerol phosphate synthase. Biochemistry 2005, 44:11974-11985.

15. Raschle T, Amrhein N, Fitzpatrick TB: On the two components of pyridoxal 5'phosphate synthase from Bacillus subtilis. J Biol Chem 2005, 280:32291-32300.

16. Feng L, Sheppard K, Tumbula-Hansen D, Soll D: Gln-tRNAGln formation from GlutRNAGIn requires cooperation of an asparaginase and a Glu-tRNAGIn kinase. $J$ Biol Chem 2005, 280:8150-8155.

17. Mouilleron S, Golinelli-Pimpaneau B: Domain motions of glucosamine-6P synthase: comparison of the anisotropic displacements in the crystals and the catalytic hingebending rotation. Protein Sci 2007, 16:485-493.

18. Goto M, Omi R, Nakagawa N, Miyahara I, Hirotsu K: Crystal structures of CTP synthetase reveal ATP, UTP, and glutamine binding sites. Structure 2004, 12:1413-1423. 19. Douangamath A, Walker M, Beismann-Driemeyer S, Vega-Fernandez MC, Sterner R, Wilmanns M: Structural evidence for ammonia tunneling across the (beta alpha)(8) barrel of the imidazole glycerol phosphate synthase bienzyme complex. Structure (Camb) 2002, 10:185-193.

20. Chaudhuri BN, Lange SC, Myers RS, Davisson VJ, Smith JL: Toward understanding the mechanism of the complex cyclization reaction catalyzed by imidazole glycerolphosphate synthase: crystal structures of a ternary complex and the free enzyme. Biochemistry 2003, 42:7003-7012.

21. Omi R, Mizuguchi H, Goto M, Miyahara I, Hayashi H, Kagamiyama H, Hirotsu K: Structure of imidazole glycerol phosphate synthase from Thermus thermophilus HB8: open-closed conformational change and ammonia tunneling. J Biochem (Tokyo) 2002, 132:759-765.

22. Amaro RE, Sethi A, Myers RS, Davisson VJ, Luthey-Schulten ZA: A network of conserved interactions regulates the allosteric signal in a glutamine amidotransferase. Biochemistry 2007, 46:2156-2173.

23. Zein F, Zhang Y, Kang YN, Burns K, Begley TP, Ealick SE: Structural insights into the mechanism of the PLP synthase holoenzyme from Thermotoga maritima. Biochemistry 2006, 45:14609-14620.

24. Strohmeier M, Raschle T, Mazurkiewicz J, Rippe K, Sinning I, Fitzpatrick TB, Tews I: Structure of a bacterial pyridoxal 5'-phosphate synthase complex. Proc Natl Acad Sci U S A 2006, 103:19284-19289. 


\section{Supplementary Figure 1}
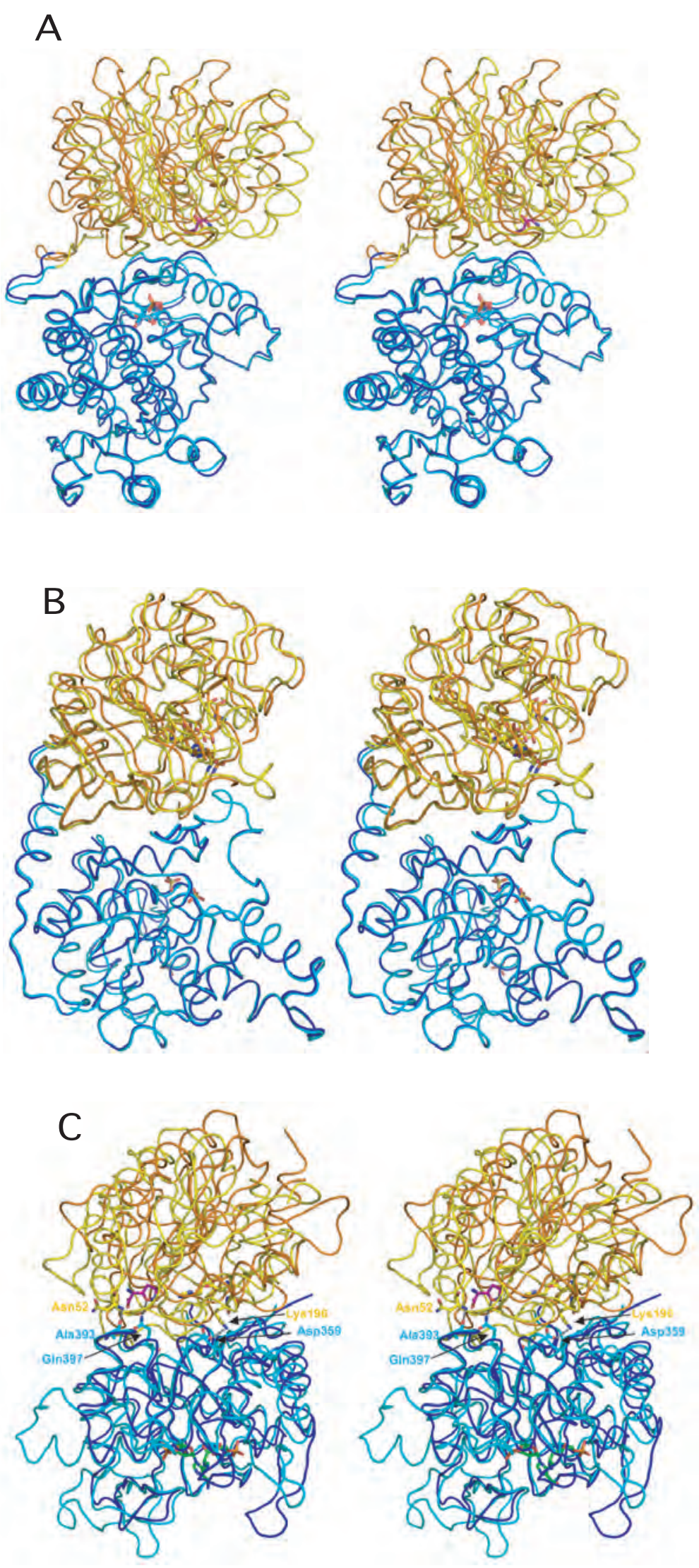
Supplementary Figure 2

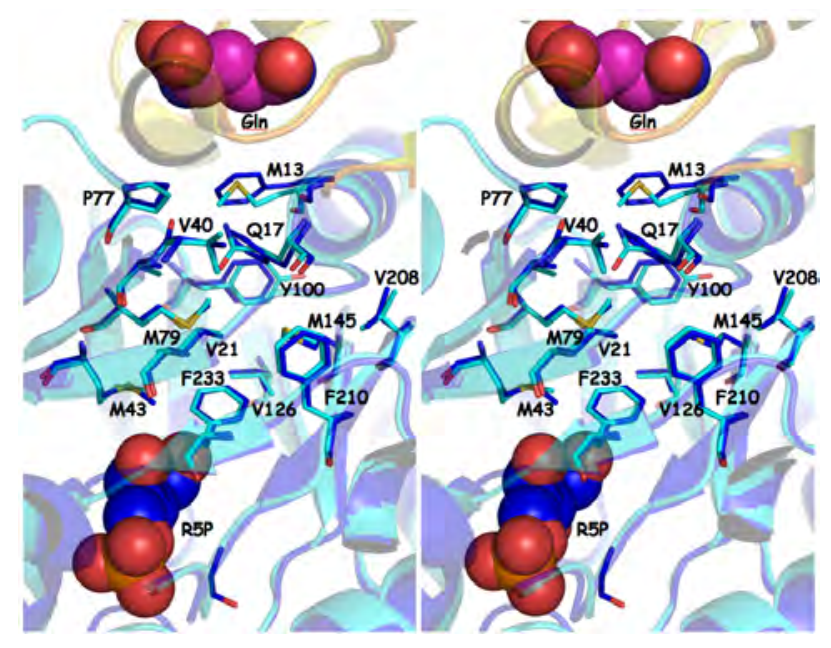

